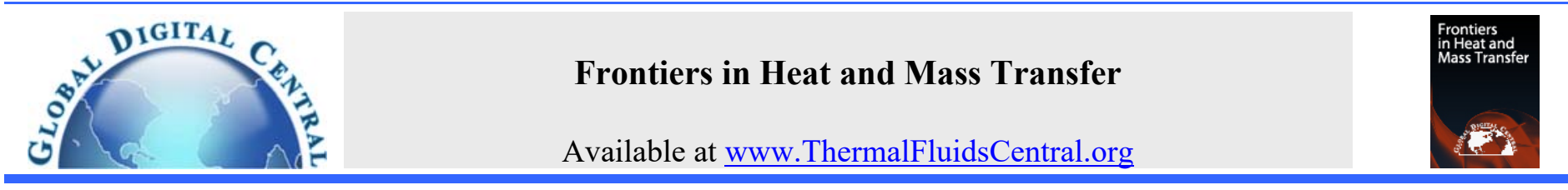

\title{
A REVIEW ON COOLING OF DISCRETE HEATED MODULES USING LIQUID JET IMPINGEMENT
}

\author{
Naveen G. Patil, Tapano Kumar Hotta ${ }^{*}$ \\ School of Mechanical Engineering, VIT Vellore - 632014, TamilNadu, India
}

\begin{abstract}
The manuscript deals with the critical review for cooling of discrete heated electronic components using liquid jet impingement. Cooling of electronic components has been a lead area of research in recent years. Due to the rapid growth of electronic industries, there is an enormous rise in the system power consumption, and the reduction in the size of electronic components has led to a rapid increase in the heat dissipation rate per unit volume of components. The present paper deals with the role of liquid jet impingement (heat flux removal rate $200-600 \mathrm{~W} / \mathrm{cm}^{2}$ ) for cooling of electronic components. The type of working fluids (Water / Fluorocarbon liquids / Dielectric fluids / Nanofluids) used for cooling, mode of heat transfer (Natural / Forced / Mixed) from electronic components, and the method of analysis (Experimental / Numerical / Combination of both) greatly influence the cooling mechanism. The electronic components considered in the present study are limited to microelectronic chips, VLSI circuit chips, integrated circuits (IC) chips and resistors. Most of the literature is pertinent to cooling of square heat sources, and many of the researchers have also focused on the comparative studies using different working fluids. Results suggest that Fluorocarbon liquids can be used for higher heat flux removal due to their high boiling point. The temperature drop obtained from the electronic components using liquid jet impingement was found to be in the range of 80 $85^{\circ} \mathrm{C}$.
\end{abstract}

Keywords: Discrete heat source, Electronic component, Heat transfer enhancement, Liquid jet impingement, Review, Thermal management

\section{INTRODUCTION}

The growth of electronic industries along with the miniaturization of electronic components has led to an enormous increase in the power density for integrated circuit (IC) chips. The key challenge for the researchers is to remove the increasing heat flux demand rate (300 $\mathrm{W} / \mathrm{cm}^{2}$ ) and to control the highly non-uniform power dissipation from the components. The various factors responsible for the failure of electronic components (Reynell, 1990) are humidity (16\%), vibration $(24 \%)$, dust $(6 \%)$, and temperature $(54 \%)$. It confirms that temperature leads the chart for the failure of electronic equipment, and must have to be controlled with great interest. The electronic industries are facing a stiff challenge for maintaining the component temperature below $85^{\circ} \mathrm{C}$ (Joshi and Paje, 1991), failing which, the system reliability may decrease by $50 \%$. The integrated circuit chips mounted on the printed circuit board (PCB) are made of Silicon, which is very sensitive to temperature due to strong energy band gaps. Hence, thermal management is critical and inevitable for electronic applications.

\subsection{Different Cooling Techniques}

Several cooling techniques are used for the electronic components; the choice of technique depends on the application. Active and passive are the two important cooling methods among them. Passive cooling methods like natural convection air cooling, thermoelectric cooling, heat pipes, and phase change based cooling do not need any external energy for heat removal from the electronic components and are used for low heat flux removal rate. However, active cooling offers high cooling capacity and requires the application of external energy in terms of fan or blower for heat removal from the electronic components. Forced convection air cooling, liquid cooling, spray cooling, jet impingement cooling, refrigeration cooling etc., fall into this category. Among this, air cooling technique is used for small heat flux levels $\left(37.5 \mathrm{~W} / \mathrm{cm}^{2}\right)$ and is not effective and sufficient to deal with the increasing heat flux demand from the electronic components. Hence, the industries are in search of better techniques in the form of liquid cooling (used high heat flux level, 200-600 W/cm²) (Schafer et al., 1991).

\subsection{Jet Impingement Cooling}

Jet impingement (Cho et al., 2011) is one of the most important liquid cooling techniques used for different industrial applications like paper drying, textiles, annealing of metal, tempering of glass, cooling of electronic equipment etc. Here high-velocity fluid is ejected in the form of a jet from a slot or small hole that is imparted on target surfaces of different geometries like circular, concave, etc. For size and space optimization, the jets are kept normal to the target surface.

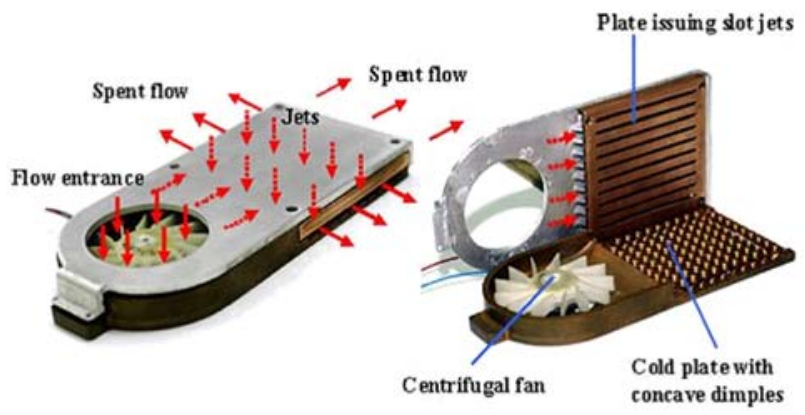

Fig. 1: Schematic diagram of jet impinging cooling in the central processing unit (CPU) (Chang et al., 2007)

\footnotetext{
"Corresponding Author Email: tapanhota@gmail.com
} 
Jets are categorized into submerged and non-submerged on the basis of the medium on which they act; when the jet medium is same as that of surrounding medium, it is known as submerged jet, and if jet medium and surrounding mediums are different, then it is a non-submerged jet (Karwa, 2012). The jet impingement phenomenon in the central processing unit (CPU) of a computer (Chang et al., 2007) is shown in Fig. 1.

\section{EFFECT OF WORKING FLUIDS ON COOLING OF ELECTRONIC MODULES USING LIQUID JET IMPINGEMENT}

Numerous work has been reported for the cooling of electronic modules using different working fluids like Water, Fluorocarbon liquids (FC-72, FC-75, FC-77, FC-87), Dielectric fluids (R-113, HFE-7200), Nanofluids $\left(\mathrm{Al}_{2} \mathrm{O}_{3}, \mathrm{CuO}, \mathrm{TiO}_{2}\right)$ etc. The working fluids were chosen on the basis of their boiling point (Lee et al., 1988) that helps for better heat removal rate from the electronic components, and for maintaining their cooling level at optimal. The liquids used in the cooling of discrete heated modulus must meet several requirements depending on the specific applications. For better understanding, the present review has been categorized under different working fluids that are considered for the study.

\subsection{Water as Working Fluid}

Water is having high specific heat that leads to the requirement of smaller mass flow rate. It has a higher value of the latent heat of vaporization due to low freezing point and high boiling point value. Water is also nontoxic and low viscous. However, water is highly corrosive as compared to other fluids.

The cooling of ICs using water jets was carried out by (Maddox et al., 2016) that has resulted in a temperature drop of $45-60^{\circ} \mathrm{C}$ from them. (Bhowmik et al., 2003) has carried out cooling of four in-line square IC chips $(10 \mathrm{~mm} \times 10 \mathrm{~mm})$ using $3 \times 3$ water jets with different flow rates. However (Whelan et al., 2012; Singh et al., 2016) predicted a temperature drop of $60^{\circ} \mathrm{C}$ while carrying out experiments on CPU. (Singh et al., 2016) carried out numerical and experimental studies on cooling (heat flux removal rate of around $150 \mathrm{~W} / \mathrm{m}^{2}$ ) of CPU units using both Nano-fluid and water. Similarly, the microprocessor board (Sharma et al., 2012) was cooled to a temperature of $65^{\circ} \mathrm{C}$ under water cooling medium (heat flux removal rate of $2-3 \mathrm{~W} / \mathrm{cm}^{2}$ ). The cooling of VLSI chips was carried out by (Kandilkar and Bapat, 2007; Heindel et al., 1995; Kiper, 1984) using water and FC-77, which is used for a heat flux removal of $500-1000 \mathrm{~W} / \mathrm{cm}^{2}$. The $3 \times 3$ array of flush mounted square VLSI chips under the same cooling medium $\left(1200 \mathrm{~W} / \mathrm{cm}^{2}\right)$ that has led to a temperature drop of $80^{\circ} \mathrm{C}$ from the chips has been studied by (Heindel et al., 1995), while (Kiper, 1984) has considered square VLSI chips that has led to a heat flux reduction by as much as $28 \%$. The experimental and numerical investigations of high power density electronic components under single-phase liquid cooling medium were studied by (Agbim, 2017). He found that the vertical cooling test sections generated a lower thermal resistance as compared to the horizontal one. (Chang, 1998) investigated numerically and experimentally the cooling of high heat flux $\left(17 \mathrm{MW} / \mathrm{m}^{2}\right)$ electronic modules using high-velocity water jets. The boiling for these electronic modules is expected only for fluxes above $20 \mathrm{MW} / \mathrm{m}^{2}$.

\subsection{FC-72 as Working Fluid}

The cooling of four chips has been carried out by (Bhowmik and Tou, 2005) using both FC-72 and water, and the comparison is shown in Fig. 2. The figure has shown the decrease in heat transfer coefficient (Nusselt number) by increasing the heating time of chips for both the working fluids; water and FC-72. It is found from the Fig. 2 that, the cooling is more effective using FC-72. It is seen that after $75 \mathrm{~s}$, the Nusselt number of the four chips do not change significantly with time. However, during the entire power-on transient operation, the Nusselt number decreased continuously.

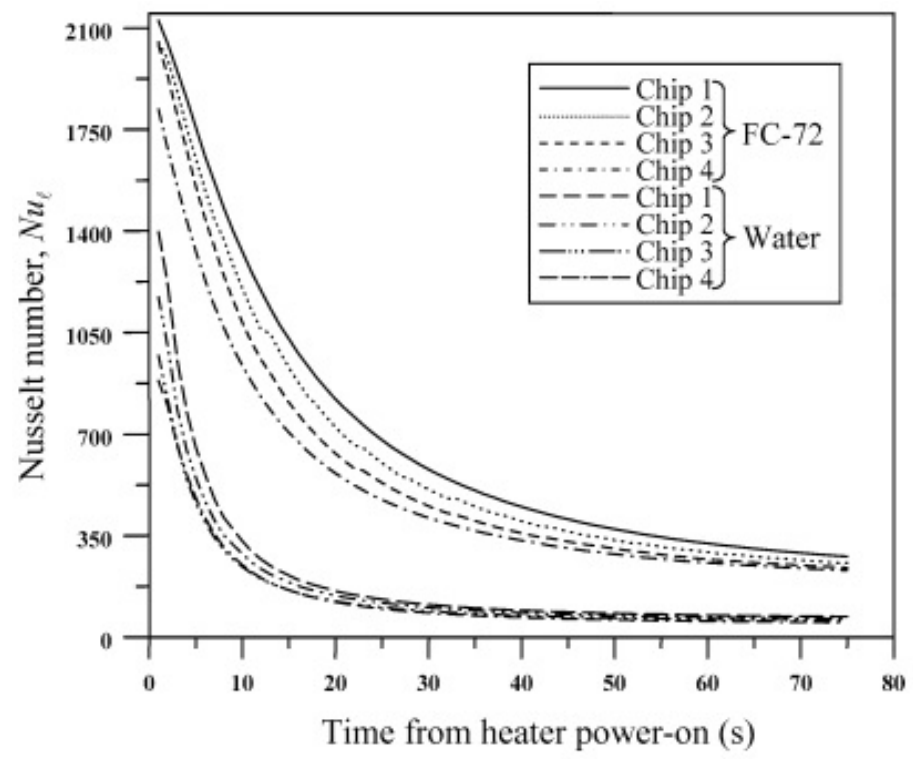

Fig. 2: Comparison of cooling of four chips using FC-72 and water (Bhowmik and Tou, 2005)

An empirical correlation between Nusselt number, Peclet number, and Fourier number was developed by (Bhowmik et al., 2003), and is given in Eq. 1. The equation predicted the transient behavior of electronic chips. The Eq. 1 has a regression coefficient of 0.96 with an RMS error of $6 \%$ on the estimate, and is valid for the following range of parameters, $1050 \leq \mathrm{Re}_{\mathrm{l}} \leq 2625,2 \leq \mathrm{q} \leq 8,1 \leq \mathrm{t} \leq 75$.

$\frac{\mathrm{Nu}_{1}}{\mathrm{Pe}_{1}{ }^{0.33}}=26.61 \mathrm{~F}_{0}^{0.41}$

The comparison of subcooling effects for different working fluids (Lee et al., 1988) is shown in Fig. 3.

It has been clear from the Fig. 3 that, FC-72 can be used for higher heat removal from the electronic components. FC- 84 has the strongest sub-cooling effect as compared to R-113 and water, which are having progressively weaker effects. This is due to the different latent heat values among the fluids.



Fig. 3: Comparison of subcooling effect for different working fluids (Lee et al., 1988) 
The cooling of resistors has been carried out by (Anwarulla, 2011; Cheng et al., 2001; Baker, 1972) using different working fluids like water, FC-72, Freon 113 and dielectric liquid. Cylindrical electric resistors (size $0.1 \mathrm{~m}$ diameter and $0.02 \mathrm{~m}$ thickness) (Anwarulla, 2011), film resistors (size $25.4 \mathrm{~mm} \times 12.7 \mathrm{~mm} \times 1 \mathrm{~mm}$ ) (Cheng et al., 2001), and resistors of size $(2 \mathrm{~cm} \times 0.01 \mathrm{~cm})$ (Baker, 1972) were considered for the study. In all the cases, it has been found that nozzle to target plate spacing, jet velocity, jet diameter, and inlet subcooling has a strong effect on the heat transfer rate from the resistors. Air cooling is very much effective during free convection for the resistors (Baker, 1972), while in case of forced convection; liquid cooling is preferred over air cooling, as the heat transfer is enhanced by a factor of 10 using liquid cooling. The cooling (heat flux removal of $310 \mathrm{~W} / \mathrm{cm}^{2}$ ) of high power electronics was carried out by (Fabbri and Dhir, 2005) using arrays of microjets using deionized water and FC-40. They also studied the effect of convective heat transfer on the Reynolds number, Prandtl number, and nozzle to plate distance on heat transfer rate. FC-72 was used as a coolant by (Mudawar and Maddox, 1990; Wang et al., 1999) for cooling of square electronic components $(12.7 \mathrm{~mm} \times 12.7 \mathrm{~mm})$, and was seen that, the temperature of electronic components was dropped by $10 \%$ as compared to single phase cooling (Wang et al., 1999). However, the two-phase cooling effect was found to be more pronounced under natural convection mode as compared to the liquid jet impingement phenomenon.

\subsection{Nano-fluid as Working Fluid}

Nano-fluids can reduce the pumping power requirement as compared to other conventional fluids due to its lower viscosity value and lower specific heat. However, the fluid is very expensive.

The cooling of the central processing unit (CPU) of the personal computer is carried out by (Naphon and Wongwises, 2011) using microchannels impinged with Nano-fluids. The comparison between 3 types of Nano-fluids $\left(\mathrm{TiO}_{2}, \mathrm{CuO}, \mathrm{Al}_{2} \mathrm{O}_{3}\right)$ under water medium was carried out by (Teamah and Khairat, 2015), and concluded that the rate of heat transfer is maximum for $\mathrm{CuO}$ /water Nano-fluids, and minimum for $\mathrm{TiO}_{2}$ /water Nano-fluids, which predicts the cooling of electronic components. (Roberts and Walker, 2010) carried out experimental studies to determine the convective heat transfer characteristics of waterbased alumina Nano-fluid (particle size 20-30 nm) used for the cooling of CPU. They found an enhancement of up to $1.5 \%$ by volume in the convective heat transfer. (Sohel et al., 2014) performed experiments on minichannels to determine the heat transfer enhancement (up to $18 \%$ ) using water-based alumina nanoparticles (volume fraction of 0.10 to $0.25 \%$ ). (Chein and Chuang, 2007) studied the performance of heat sinks using Nano-fluids, and found that, nano-fluid cooled microchannel heat sinks (MCHS) absorb more energy than water-cooled MCHS at low flow rates. (Chen and Ding, 2011) studied the heat transfer characteristics and cooling performance of a microchannel heat sinks with water-based alumina Nano-fluids using different nanoparticle volume fraction. (Ijam and Saidur, 2012) investigated experimentally the cooling of the electronic device under Nano-fluids (Sic-water with the volume fraction of $4 \%$ and $\mathrm{TiO}_{2}$-water with the volume fraction of $12.44 \%$ ).

\subsection{Dielectric Fluids (HFE) as Working Fluid}

The dielectric fluid has a wide range of boiling point. It has also low density, low boiling point and easy to evaporate. However, the demerit is that it has low critical heat flux value. Hence, the rate of heat dissipation from the electronic components using dielectric fluids will be much lower as compared to other fluids.

The cooling (heat removal rate of $100 \mathrm{~W} / \mathrm{cm}^{2}$ ) of integrated square electronics chips using dielectric fluids, HEE-7200 and HFE-8401 and embedded droplet impingement technique (EDIFICE) was carried by (Amon et al., 2005; Lou et al., 2005). They made a comparison between water and dielectric HEE-7200 fluid and found that the dielectric fluid has low viscosity, low surface tension, and has better atmospheric performance, and can be used for higher heat removal and thus lead to better thermal management systems. The cooling of microelectronic equipment has been analyzed (Honnor and Thomas, 1969) to obtain their best optimal design. The researchers have used direct cooling methods like forced, laminar and mixed convection mode of heat transfer to predict the component temperature accurately. The experimental investigation was carried out by (Bhowmik and Tou, 2005) to study the single-phase transient heat transfer from square electronic chips $(10 \mathrm{~mm}$ $\mathrm{x} 10 \mathrm{~mm}$ ) under different protrusion heights. They observed that flow separation and vortex shedding due to protrusion leads to decrease in the average Nusselt number with time. The comparison between flush and protruded heat sources was carried out by (Bhowmik and Tou, 2005). An empirical correlation was proposed by (Bhowmik and Tou, 2005) for the electronic chips under the transient forced convection as given in Eq. 2. This equation is used to predict the transient heat transfer behavior of chips.

$\mathrm{Nu}_{\mathrm{l}}=0.776\left(\mathrm{Pe}_{\mathrm{l}}\right)^{0.33}\left(\mathrm{~F}_{\mathrm{o}}\right)^{-0.744}$

The Eq. 2 has a regression coefficient of 0.992 with an RMS error of $3.5 \%$ on the estimate and is valid for the following range of parameters, $800 \leq \mathrm{Re}_{\mathrm{l}} \leq 2625,1 \leq \mathrm{q} \leq 7,0 \leq \mathrm{t} \leq 75$.

The cooling of Silicon substrates was experimentally investigated by (Jaeger et al., 1989) under direct immersion cooling using Freon-12. They have compared the results with liquid jet impingement cooling of the same substrate and found that liquid jet impingement technique can be useful for a heat flux removal rate of $200 \mathrm{~W} / \mathrm{cm}^{2}$ with a maximum temperature rise for chips of the order of $50^{\circ} \mathrm{C}$.

The temperature drop and amount of heat flux removal from different electronic components using different cooling fluids along with shape and size of components are given in Table 1. It is seen that most of the researchers have focused on cooling of electronic components under water medium, with maximum heat flux removal up to $200-300 \mathrm{~W} / \mathrm{cm}^{2}$, and temperature drop up to $40-65^{\circ} \mathrm{C}$.

\section{EFFECT OF MODES OF HEAT TRANSFER ON COOLING OF ELECTRONIC MODULES USING LIQUID JET IMPINGEMENT}

Convective heat transfer (Incropera, 1988) is a predominant mode of heat removal from the electronic components which are further categorized into natural, forced and mixed convection. The detailed explanation of different cooling techniques used for electronic components is reported under section (Bhowmik and Tou, 2005; Nayaki et al., 2017). For better understanding, the present review is further categorized under different modes of heat transfer, which are considered in the present study.

\subsection{Natural Convection Mode of Cooling}

The numerical and experimental investigation of natural convection heat transfer from four in-line square arrays of flush mounted and protruded microelectronic chips is carried out by (Nayaki et al., 2017). The computational study was based on four different working fluids, like, water $\left(\mathrm{Pr}=5, \mathrm{BP}=100^{\circ} \mathrm{C}\right), \mathrm{FC}-72\left(\mathrm{Pr}=9, \mathrm{BP}=56^{\circ} \mathrm{C}\right), \mathrm{FC}-77(\mathrm{Pr}=25$, $\left.\mathrm{BP}=97^{\circ} \mathrm{C}\right)$ and ethylene glycol $\left(\mathrm{Pr}=130, \mathrm{BP}=197.3^{\circ} \mathrm{C}\right)$, and has resulted in a temperature drop of $20-30^{\circ} \mathrm{C}$ from the chips.

\subsubsection{Laminar jet}

The experimental and numerical investigation of four in-line electronic chips under natural convection heat transfer was carried out by (Bhowmik and Tou, 2005; Tou et al., 1998), and found that the heat fluxes, coolant flow rate and other geometrical parameters greatly affect the heat transfer rate from the chips. (Bhowmik and Tou, 2005) have also proposed a correlation for each chip, as given in Eq. 3. The equation is used to predict the transient behavior of each chip. 
Table 1 Effect of cooling fluid on temperature drop or heat flux removal from electronic components using liquid jet impingement

\begin{tabular}{|c|c|c|c|c|}
\hline $\begin{array}{l}\text { Sl. } \\
\text { no. }\end{array}$ & Author (s) & Cooling fluid & $\begin{array}{l}\text { Temperature drop / } \\
\text { Heat flux removal }\end{array}$ & $\begin{array}{l}\text { Electronic Component } \\
\text { (Size) }\end{array}$ \\
\hline 1 & Maddox et al., 2016 & Water & $45-60^{\circ} \mathrm{C}$ & $\begin{array}{l}\text { Rectangular copper blocks } \\
(1.27 \mathrm{~cm} \times 10.16 \mathrm{~cm})\end{array}$ \\
\hline 2 & Whelan et al., 2012 & Water & $200 \mathrm{~W}, 65^{\circ} \mathrm{C}$ & $\begin{array}{l}\text { Square chips } \\
(8.24 \mathrm{~cm} \times 8.24 \mathrm{~cm})\end{array}$ \\
\hline 3 & Anwarulla , 2011 & Water & $45^{\circ} \mathrm{C}$ & $\begin{array}{l}\text { Resistor } \\
(100 \text { mm diameter and } 2 \\
\text { mm thick })\end{array}$ \\
\hline 4 & Cheng et al., 2001 & FC-72 & $60^{\circ} \mathrm{C}, 60-70 \mathrm{~W} / \mathrm{cm}^{2}$ & $\begin{array}{l}\text { Rectangular chips } \\
(12.7 \mathrm{~mm} \times 8 \mathrm{~mm})\end{array}$ \\
\hline 5 & $\begin{array}{l}\text { Naphon and } \\
\text { Wongwises, } 2011\end{array}$ & $\begin{array}{l}\text { Water with } \mathrm{TiO}_{2} \\
\text { suspended Nano-particles }\end{array}$ & $5^{\circ} \mathrm{C}$ & CPU unit \\
\hline 6 & Fabbri and Dhir, 2005 & $\begin{array}{l}\text { Deionized water and FC- } \\
40\end{array}$ & $310 \mathrm{~W} / \mathrm{cm}^{2}$ & $\begin{array}{l}\text { Microelectronic chips } \\
(1.27 \mathrm{~cm} \times 1.27 \mathrm{~cm})\end{array}$ \\
\hline 7 & Bhowmik et al., 2003 & Water & $2-8 \mathrm{~W} / \mathrm{cm}^{2}$ & $\begin{array}{l}\text { Square IC chips } \\
(1 \mathrm{~cm} \times 1 \mathrm{~cm})\end{array}$ \\
\hline 8 & Bhowmik and Tou, 2005 & FC-72 & $1-7 \mathrm{~W} / \mathrm{cm}^{2}$ & $\begin{array}{l}\text { Square chips } \\
(1 \mathrm{~cm} \times 1 \mathrm{~cm})\end{array}$ \\
\hline 9 & Amon et al., 2005 & HFE 7200 & $45 \mathrm{~W} / \mathrm{cm}^{2}$ & $\begin{array}{l}\text { Square chip } \\
(2.54 \mathrm{~cm} \times 2.54 \mathrm{~cm})\end{array}$ \\
\hline 10 & Kiper, 1984 & Water & $500 \mathrm{~W} / \mathrm{cm}^{2}$ & \begin{tabular}{|l|} 
VLSI circuits \\
$(8 \mathrm{~cm} \times 8 \mathrm{~cm})$
\end{tabular} \\
\hline 11 & $\begin{array}{l}\text { Honnor and } \\
\text { Thomas, } 1969\end{array}$ & FC-72 and FC -87 & $100 \mathrm{~W} / \mathrm{cm}^{2}$ & \begin{tabular}{|l|} 
Square chips \\
$(1.27 \mathrm{~cm} \times 1.27 \mathrm{~cm})$
\end{tabular} \\
\hline 12 & Teamah and Khairat, 2015 & \begin{tabular}{|l|} 
Water with 3 types of \\
suspended $\mathrm{Nano}$-particles \\
$\mathrm{TiO}_{2}, \mathrm{CuO}, \mathrm{Al}_{2} \mathrm{O}_{3}$ \\
\end{tabular} & $75 \mathrm{~W}$ & Flat plate \\
\hline 13 & Bhowmik and Tou, 2005 & Water & $1-7 \mathrm{~W} / \mathrm{cm}^{2}$ & $\begin{array}{l}\text { Square chips } \\
(1 \mathrm{~cm} \times 1 \mathrm{~cm})\end{array}$ \\
\hline 14 & Jaeger et al., 1989 & Freon-12 & $150 \mathrm{~W} / \mathrm{cm}^{2}$ & $\begin{array}{l}\text { Silicon hybrid multiple } \\
\text { chip packaging }\end{array}$ \\
\hline 15 & $\begin{array}{l}\text { Mudawar and } \\
\text { Maddox, } 1989\end{array}$ & FC-72 & $106 \mathrm{~W} / \mathrm{m}^{2}$ & \begin{tabular}{|l|} 
Square chips \\
$(1.27 \mathrm{~cm} \times 1.27 \mathrm{~cm})$
\end{tabular} \\
\hline 16 & Sharma et al., 2012 & Water & $100 \mathrm{~W}, 40.7-50^{\circ} \mathrm{C}$ & Microprocessor chips \\
\hline 17 & Wang et al., 1999 & Water and FC-72 & $1.3-5.4 \mathrm{~W} / \mathrm{cm}^{2}$ & $\begin{array}{l}\text { High performance } \\
\text { electronic device }(23.3 \mathrm{~cm} \\
\times 16 \mathrm{~cm})\end{array}$ \\
\hline 18 & Agbim, 2017 & Water & $180-230 \mathrm{~W} / \mathrm{cm}^{2}$ & $\begin{array}{l}\text { Power electronic devices } \\
\text { (MOSFETs, HEMTs, } \\
\text { \&IGBTs }\end{array}$ \\
\hline 19 & Roberts and Walker, 2010 & $\begin{array}{l}\text { Aluminum - Water } \\
\text { nanoparticles }\end{array}$ & & Copper blocks \\
\hline 20 & Sohel et al., 2014 & $\begin{array}{l}\mathrm{Al}_{2} \mathrm{O}_{3}-\text { Water } \\
\text { nanoparticles }\end{array}$ & & \begin{tabular}{|l|} 
Copper channel \\
$(5 \mathrm{~cm} \times 5 \mathrm{~cm} \times 1 \mathrm{~cm})$
\end{tabular} \\
\hline 21 & Chein and Chuang, 2007 & CuO-Water Nanofluid & & Microchannel heat sink \\
\hline 22 & Chen and Ding, 2011 & $\mathrm{Al}_{2} \mathrm{O}_{3}$-Water nanoparticles & & $\begin{array}{l}\text { Microchannel heat sink } \\
(5 \mathrm{~cm} \times 1.6 \mathrm{~cm})\end{array}$ \\
\hline 23 & Ijam and Saidur, 2012 & $\begin{array}{l}\mathrm{SiC} \text {-water and } \mathrm{TiO}_{2} \text {-water } \\
\text { Nanofluids }\end{array}$ & & $\begin{array}{l}\text { Mini channel heat sink } \\
(20 \mathrm{~cm} \times 20 \mathrm{~cm})\end{array}$ \\
\hline
\end{tabular}

$\mathrm{Nu}_{1}=0.31 \mathrm{Fo}^{-0.23}\left(\mathrm{Ra}^{*}\right)^{0.25}$

The Eq. 3 has a regression coefficient of 0.996 with an RMS error of $2 \%$ on the estimate and is valid for the following range of parameters, $800 \leq \operatorname{Re}_{1} \leq 2625,1 \leq \mathrm{q} \leq 7,0 \leq \mathrm{t} \leq 75$.

The experimental determination of natural and forced convective heat transfer from small electronic devices was carried out by (Baker, 1972). They predicted that average convective heat transfer coefficient increased significantly, as the size of the heat source reduced. They used Freon 113 and silicon dielectric liquid for cooling the microelectronic devices, where, the average convective heat transfer rate was varied from $0.2-3 \mathrm{~W} / \mathrm{cm}^{2}$, and the heat flux was maintained at $100 \mathrm{~W} / \mathrm{cm}^{2}$. The experimental investigation of steady and transient heat transfer from eight in-line rectangular heated protrusions in a vertical channel under the natural convection was reported by (Joshi et al., 1989), using water, and concluded that, for smaller spacing, the component surface temperature increased significantly due to the reduction in fluid velocities.

\subsection{Force Convection Mode of Cooling}

\subsubsection{Laminar jet}

The cooling (heat flux removal of $310 \mathrm{~W} / \mathrm{cm}^{2}$ ) of high power electronics was carried out by (Fabbri and Dhir, 2005) using arrays of microjets with 
deionized water and FC-40. They also studied the effect of convective heat transfer on Reynolds number, Prandtl number, and nozzle to plate distance on heat transfer rate.

\subsubsection{Turbulent jet}

The experimental investigations on arrays of free and submerged jet cooling of electronic devices under water medium are carried out by (Robinson and Schnizler, 2007) under forced convection mode. The study has shown that the free jet configuration was found to behave thermally as a submerged jet within the range of $2<\mathrm{H} / \mathrm{d}<10$. Beyond this, a transition to entirely free-jet flow occurs, and the heat transfer coefficient has improved marginally with increasing the jet to target plate spacing. The spray cooling techniques can be used for multiple arrays of sprays to cool the ICs, by varying the heat flux from $50-150 \mathrm{~W} / \mathrm{cm}^{2}$, however for higher heat flux removal $\left(500-1000 \mathrm{~W} / \mathrm{cm}^{2}\right)$, microchannels were effective (Kandilkar and Bapat, 2007). The comparative study of the jet impingement, spray and microchannel cooling using water jets under forced convection was carried out by (Kandilkar and Bapat, 2007). (Leena et al., 2018) carried out experimental and numerical work on high power electronic components using multiple jet impingements. They varied the Reynolds number (4000-8000) and jet-to-jet spacing and found that at Reynolds number $(\operatorname{Re}=5000)$ optimal cooling can be achieved. They have also proposed a correlation (given in Eq. 4) between the average Nusselt numbers in terms of Reynolds number. The equation suggests that the fluid-heater interactive surface would influence the boiling heat transfer more significantly. The Eq. 4 is valid for the following range of parameters, $4000 \leq \operatorname{Re} \leq 8000$.

$\mathrm{Nu}_{\text {avg }}=0.044 \mathrm{Re}^{0.58}$

(Schafer et al., 1991) investigated experimentally the average heat transfer coefficient for multiple square discrete heat sources under FC 72 medium. They observed that the Prandtl number is predominant to calculate the heat flux dissipation from the heated surfaces by maintaining the temperature difference between the heater surface and the liquid at $50^{\circ} \mathrm{C}$. For water $(\operatorname{Pr}=7)$ and FC-77 $(\operatorname{Pr}=25)$, the heat flux dissipation from the heated surfaces is approximately $250 \mathrm{~W} / \mathrm{cm}^{2}$ and 40 $\mathrm{W} / \mathrm{cm}^{2}$ respectively. The experimental investigation of forced convection cooling for arrays of protruding discrete heat sources with definite heat input values is carried out by (Gupta and Jaluria, 1998). The test section consisted of four rows, each of three chips, and the chips were mounted at both top and bottom of the rectangular channel. The average heat transfer coefficient for different heat inputs did not show any appreciable change for arrays of heat sources (Gupta and Jaluria, 1998). The average Nusselt number value also decreased with increase in the channel height. The experimental study for cooling of simulated microelectronic chips of square size $(12.7 \mathrm{~mm} \times 12.7 \mathrm{~mm})$ using water and flour carbon fluid is carried out by Mudawar and Maddox, 1990). It was seen that the Reynolds number was independent of heat transfer from the heat sources, and for turbulent jets, heat transfer was enhanced by approximately $25 \%$.

\subsubsection{Phase change cooling phenomenon}

(Cheng et al., 2001) carried out experiments to investigate the free jet impingement boiling phenomenon. The Jet velocity, jet diameter, and inlet sub-cooling clearly influenced the boiling heat transfer and critical heat flux. Higher velocity brought higher heat transfer coefficient in both single phase and boiling. The single-phase forced convection heat transfer from four in-line simulated flush mounted square electronic chips (10 $\mathrm{mm} \times 10 \mathrm{~mm}$ ) under water medium was carried out by (Tso et al., 1999). They suggested that the data from air-cooling may be used to predict the heat transfer characteristic of liquid cooling for similar geometry by considering the Prandtl number scaling. Experimental investigations were carried out by (Gersey and Muddawar, 1992) for different channel orientations to study the effect of critical heat flux
(CHF) form nine in-line square microelectronic chips using FC-72. It was found that lowest CHF occurred when the bubbles stagnated on the chip surface. The forced convection boiling heat transfer regimes was studied experimentally by (Willingham and Muddwar, 1992) for nine in-line square microelectronic electronic chips $(10 \mathrm{~mm} \times 10 \mathrm{~mm})$ which were flush mounted on a vertical channel filled with FC-72. They observed that the chips which were in the upstream had experienced a larger drop in temperature. Boiling incipience and critical heat flux (CHF) for all the chips were delayed to higher heat flux with increasing velocity or subcooling. Because of some unusual boiling activity on Chip 1, the authors believe that electronic cooling applications would benefit from the positioning of a heated plate upstream of the array of electronic chips in order to provide more uniform and predictable boiling on the surfaces of downstream chips.

The study has delineated three distinct heat transfer regions, laminar, the transition from laminar to turbulent, and turbulent, and concluded that Nusselt number of each chip is a strong function of Peclet number. The experimental analysis of IC chips was carried out by (Womac et al., 1994) under forced convection for both free and submerged jet configurations and for a wide range of velocities, nozzle diameters, and nozzle - to - heater separation distances using water and fluorocarbon liquid as coolants. They have proposed correlations for free surface and submerged surface jet impingement.

The experimental investigation of single-phase heat transfer from four in-line square electronic chip (both flush mounted and protruding) under forced convection with FC-72 as working fluid was carried by (Tou et al., 1998), and observed that, Nusselt number for all the chips have almost same value, and the heat transfer from the protruding chips is higher than the flush mounted chips. The Reynolds number has a great effect on the rate of heat transfer from the chips. The numerical investigation of two-phase jet impingement cooling of an electronic chip (Silicon) by boiling FC-72 dielectric liquid under forced convection cooling was carried out by (Wang et al., 1999) considering Eulerian twofluid method for simulating the two-phase (liquid/vapor) flows with phase change boiling heat transfer, single phase jet impingement and natural convection two-phase cooling. They found that, the two-phase cooling results in $10 \%$ decrease in temperature of the ICs as compared to single phase cooling. The effect of forced convection cooling on microelectronic chips using FC-77 and water as cooling medium was considered by (Incropera et al., 1986; Gersey and Muddawar, 1992). The inline, four-rows of 12 flush mounted square discrete heat sources (12.7 $\mathrm{mm} \times 12.7 \mathrm{~mm}$ ) mounted on a horizontal rectangular channel filled with FC-77 and water was analyzed by (Incropera, et al., 1986), and found that, average convection coefficient for different rows of heat sources decreased by approximately $25 \%$ from the first to the second row, and by $5 \%$ from the third to fourth row. Again, the results of FC-77 were in strong agreement with water, for Reynolds number ranges of $5000<\mathrm{Re}$ $<14000$. The forced convection cooling of simulated microelectronic chips of square or rectangular size under water and Freon -12 cooling medium was studied by (Ali and Ramadhyani, 1992; Jaeger et al., 1989). The corrugated and parallel channels study was performed by (Ali and Ramadhyani, 1992), and they concluded that corrugated channels were much better than the parallel plate channels under the operating parameters like equal mass flow rate, equal pumping power, and equal pressure drop. The experimental investigation was carried out by (Tuckerman, 1984) to determine the heat transfer from the integrated circuits in water cooling medium. They observed that the heat flux removal from the IC chips was limited to $20 \mathrm{~W} / / \mathrm{cm}^{2}$.

\subsection{Mixed Convection Mode of Cooling}

\subsubsection{Turbulent jet}

The experimental investigation of mixed convection heat transfer from 4 $\mathrm{x} 3$ arrays of flush mounted IC chips of rectangular and circular geometry in a horizontal channel under FC-77 and water medium was carried out by (Mahaney et al., 1990), and found that laminar and transitional flow occurs at $\operatorname{Re}_{\mathrm{D}}<4000\left(\operatorname{Re}_{\mathrm{L}}<2600\right)$, and turbulent flow for larger 
Reynolds numbers. The increase in Rayleigh number increases the Reynolds number that ultimately enhances the heat transfer rate from the chip.

The transient mixed convection heat transfer studies were carried out by (Flores et al., 2016) from two discrete flush-mounted heaters mounted in a rectangular channel of finite length. They studied the effect of buoyancy and inclination angle using water. The higher values of heat transfer rates were achieved for horizontal position of the channel, and the buoyancy and. The cooling of electronic chips using Ethylene glycol and FC-75 was carried out by (Caromona and Keyhani, 1989), and they observed the variation of Prandtl number has a negligible effect on the Nusselt number from FC-75 to Ethylene glycol. The liquid Immersion cooling of longitudinal array of discrete heat sources was carried out experimentally by (Heindel et al., 1992) under water and FC-77 medium. They observed flow regimes ranging from mixed convection to laminar and turbulent forced convection. They found that higher Prandtl number fluids enhance the heat transfer rate significantly due to their larger value of Reynolds number.

The temperature drop and amount of heat flux removal from the electronic components under different heat transfer modes along with type and size of components are given in Table 2. It is concluded that most of the researchers have focused on forced convection technique for cooling of electronic components. The maximum heat flux removal rate achieved is of the order of $50-2000 \mathrm{~W} / \mathrm{cm}^{2}$.

Table 2 Effect of Modes of Heat Transfer on Cooling of Electronic Modules using Liquid Jet Impingement

\begin{tabular}{|c|c|c|c|c|}
\hline $\begin{array}{l}\text { Sl. } \\
\text { no. }\end{array}$ & Author(s) & $\begin{array}{l}\text { Mode of heat } \\
\text { transfer }\end{array}$ & $\begin{array}{l}\text { Temperature drop / } \\
\text { Heat flux removal }\end{array}$ & Electronic Component (Size) \\
\hline 1 & Senthil et al., 2017 & Free convection & $20-30^{\circ} \mathrm{C}$ & Square IC chips \\
\hline 2 & $\begin{array}{l}\text { Robinson and } \\
\text { Schnitzler, } 2007 \\
\end{array}$ & Forced convection & $35-40 \mathrm{~W} / \mathrm{m}^{2}$ & $\begin{array}{l}\text { Square stainless steel plate } \\
(7.8 \mathrm{~cm} \times 7.8 \mathrm{~cm})\end{array}$ \\
\hline 3 & $\begin{array}{l}\text { Kadilkar and Bapat, } \\
2007\end{array}$ & Forced convection & $80^{\circ} \mathrm{C}, 500-10000 \mathrm{~W} / \mathrm{cm}^{2}$ & $\begin{array}{l}\text { VLSI chips } \\
(1.22 \mathrm{~cm} \times 1.22 \mathrm{~cm})\end{array}$ \\
\hline 4 & Gupta and Jaluria, 1998 & Forced convection & $60^{\circ} \mathrm{C}, 60-70 \mathrm{~W} / \mathrm{cm}^{2}$ & $\begin{array}{l}\text { Square IC chips } \\
(1.27 \mathrm{~cm} \times 1.27 \mathrm{~cm})\end{array}$ \\
\hline 5 & Tso et al., 1999 & Forced convection & $5-20 \mathrm{~W} / \mathrm{cm}^{2}$ & $\begin{array}{l}\text { Square IC chips } \\
(1 \mathrm{~cm} \times 1 \mathrm{~cm})\end{array}$ \\
\hline 6 & Womac et al., 1994 & Forced convection & $50^{\circ} \mathrm{C}$ & $\begin{array}{l}\text { Square IC chips } \\
(1.27 \mathrm{~cm} \times 1.27 \mathrm{~cm})\end{array}$ \\
\hline 7 & Bhowmik et al., 2003 & Free convection & $1-7 \mathrm{~W} / \mathrm{cm}^{2}$ & $\begin{array}{l}\text { Square IC chips } \\
(1 \mathrm{~cm} \times 1 \mathrm{~cm})\end{array}$ \\
\hline 8 & Tou et al., 1998 & Forced convection & $100-200 \mathrm{~W} / \mathrm{cm}^{2}$ & $\begin{array}{l}\text { Square IC chips } \\
(1 \mathrm{~cm} \times 1 \mathrm{~cm})\end{array}$ \\
\hline 9 & Joshi et al., 1989 & Free convection & $45 \mathrm{~W} / \mathrm{cm}^{2}$ & $\begin{array}{l}\text { Rectangular chips } \\
(23.7 \mathrm{~mm} \times 7.6 \mathrm{~mm} \times 10.18 \mathrm{~mm})\end{array}$ \\
\hline 10 & Flores et al ., 2016 & Mixed convection & $727-2970 \mathrm{~W} / \mathrm{m}^{2}$ & Square heat source \\
\hline 11 & $\begin{array}{l}\text { Caromona and Keyhani, } \\
1989\end{array}$ & Free convection & $11 \mathrm{~W}$ & Heated protrusions \\
\hline 12 & Mahaney et al., 1990 & Mixed convection & $50-200 \mathrm{~W} / \mathrm{cm}^{2}$ & $\begin{array}{l}\text { Square IC chips } \\
(1.27 \mathrm{~cm} \times 1.27 \mathrm{~cm})\end{array}$ \\
\hline 13 & Wang et al., 2004 & Free convection & $100^{\circ} \mathrm{C}$ and $90 \mathrm{~W}$ & $\begin{array}{l}\text { Square IC chips } \\
(1 \mathrm{~cm} \times 1 \mathrm{~cm})\end{array}$ \\
\hline 15 & Incropera et al., 1986 & Forced convection & $80-100^{\circ} \mathrm{C}$ & $\begin{array}{l}\text { Square IC chips } \\
(1.27 \mathrm{~cm} \times 1.27 \mathrm{~cm})\end{array}$ \\
\hline 16 & $\begin{array}{l}\text { Ali and Ramadhyani, } \\
1992\end{array}$ & Forced convection & $50 \mathrm{~W} / \mathrm{cm}^{2}$ & $\begin{array}{l}\text { Square IC chips } \\
(7.6 \mathrm{~cm} \times 7.6 \mathrm{~cm})\end{array}$ \\
\hline 17 & Schafer et al., 1991 & Forced convection & $200 \mathrm{~W} / \mathrm{cm}^{2}$ & $\begin{array}{l}\text { Square IC chips } \\
(1.27 \mathrm{~cm} \times 1.27 \mathrm{~cm})\end{array}$ \\
\hline 18 & Tuckerman, 1984 & Forced convection & $20 \mathrm{~W} / \mathrm{cm}^{2}$ & IC chips \\
\hline 19 & Leena et al., 2018 & Forced convection & & $\begin{array}{l}\text { Square copper block } \\
(7.4 \mathrm{~cm} \times 7.4 \mathrm{~cm})\end{array}$ \\
\hline 20 & Heindel et al.,1992 & Forced convection & $2 \mathrm{~W}$ & 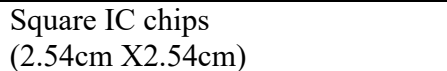 \\
\hline
\end{tabular}

\section{METHOD OF ANALYSIS FOR COOLING OF ELECTRONIC MODULES USING LIQUID JET IMPINGEMENT}

Most of the work on cooling of electronic modules using liquid jet impingement was experimental and numerical in nature. However, few analytical and comparative studies were also carried out to predict the heat transfer behavior from the electronic chips. For better understanding, the present review has been categorized into different techniques used in the present study.

\subsection{Experimental Techniques}

The experimental study was carried out by (Overholt et al., 2005) to study the performance and usage of Microjet Cooling Jet Arrays (MCJA) in electronic components. It consists of jet arrays of small diameter (300 Microns) used for removal of higher heat fluxes from $300-1000 \mathrm{~W} / \mathrm{cm}^{2}$. The experimental investigation from a hot surface was carried out by (Karwa, 2012) using an array of jets under water medium. He had obtained a maximum heat flux of $8.5 \mathrm{~W} / \mathrm{cm}^{2}$ at the stagnation point, and the values decreased away from the stagnation point. The experimental 
study to enhance the convective heat transfer from the target surface was studied by (Agrawala et al., 2014), and the maximum heat flux was obtained at maximum Reynolds number and was seen that the axial dimension (nozzle to plate distance) had minimal effect on the surface heat flux. The experimental study for cooling of simulated microelectronic chips of square size $(12.7 \mathrm{~mm} \times 12.7 \mathrm{~mm})$ using water and flour carbon fluid was carried out by (Besserman, et al., 1991; Mudawar and Maddox, 1990). It was seen that the Reynolds number was independent of heat transfer from the heat sources, and for turbulent jets, heat transfer was enhanced by approximately $25 \%$. (Besserman, et al., 1991) have performed experiments to determine the average convection coefficient for a round heater using two liquids of different Prandtl number ( $\operatorname{Pr}=7$ and 25). Data obtained for the two fluids are 'well correlated for multiple chips in terms of Nusselt number, Reynolds number, and Prandtl number, and is given in Eq. 5. The Eq. 5 is valid for the following range of parameters. $1000 \leq \mathrm{Re}_{\mathrm{d}} \leq 40000, \operatorname{Pr}=7$ (water) and 25 (dielectric fluorocarbon).

$\mathrm{Nu}_{\mathrm{d}}=0.39 \operatorname{Re}_{\mathrm{d}}{ }^{0.5} \operatorname{Pr}^{0.4}$

The experimental investigation of forced convection cooling from 3 x 3 square electronic chips using FC-72 was carried out by (Wadsworth and Mudawar, 1990). They observed that rectangular jets maintain nearly isothermal conditions at the chip surface, and the chip cooling rate was independent of channel height, and the average Nusselt number was strongly dependent on jet velocity and jet width. The analytical and experimental determination of natural and forced convective heat transfer from small electronic devices was carried out by (Baker, 1972). They predicted that average convective heat transfer coefficient increased significantly, as the size of the heat source reduced. They used Freon 113 and silicon dielectric liquid for cooling the microelectronic devices, where, the average convective heat transfer rate was varied from $0.2-3 \mathrm{~W} / \mathrm{cm}^{2}$, and the heat flux was maintained at $100 \mathrm{~W} / \mathrm{cm}^{2}$. The experimental investigation of different novel packaging methodologies for spray cooling techniques used in power semiconductor devices using dielectric liquids, FC-72 and FC-84 were carried out by (Vanam et al., 2005). They have mixed FC-72 and FC-84 to achieve maximum heat flux removal rate $\left(100 \mathrm{~W} / \mathrm{cm}^{2}\right)$, that gave the optimum design for semiconductors. The experimental investigation of Silicon microchannel coolers (having heat transfer coefficient of $130,000 \mathrm{~W} / \mathrm{cm}^{2}{ }^{\circ} \mathrm{C}$ ) for high power chips was carried out by (Colgan et al., 2007), and found that microchannel was used for high heat flux removal rate in the range of $300-400 \mathrm{~W} / \mathrm{cm}^{2}$. They estimated the maximum power density for chips using the temperature difference between the chip and ambient as $63^{\circ} \mathrm{C}$. The experimental investigation for the thermo-fluid design of singlephase submerged jet impingement cooling for electronic components was carried out by (Maddox and Bar-Cohen, 1994). They cooled $1 \mathrm{~cm}^{2}$ square heat sources (dissipating power of $100 \mathrm{~W}$ ) to $80^{\circ} \mathrm{C}$ using FC-77 at $20^{\circ} \mathrm{C}$. They found that sub-cooling. The experimental investigation was carried by (Samant and Simon, Experimental studies (Sung and Muddwar, 2006) were performed to investigate the two-phase boiling characteristics of ICs with slot jets and microchannel flow, and dielectric PF-5052 fluid. The forced convection boiling heat transfer regimes was studied experimentally by (Willingham and Muddwar, 1992) for nine inline square microelectronic electronic chips $(10 \mathrm{~mm} \times 10 \mathrm{~mm})$ which were flush mounted on a vertical channel filled with FC-72. They observed that the chips which were in the upstream had experienced a larger drop in temperature. Boiling incipience and critical heat flux (CHF) for all the chips were delayed to higher heat flux with increasing velocity or subcooling. The experimental investigation was carried by (Samant and Simon, 1989) to determine the heat transfer from a small heated patch to a subcooled fully developed turbulent flow. They observed that using R-113, the maximum heat flux was limited by the thermal deposition temperature to $2.04 \mathrm{MW} / \mathrm{m}^{2}$, for the velocity of 16.5 $\mathrm{m} / \mathrm{s}$. At a low velocity of $1.8 \mathrm{~m} / \mathrm{s}$, no boiling regimes were observed on surfaces at $80^{\circ} \mathrm{C}$. They have developed a correlation between Nusselt number, Reynolds number and Prandtl number of chips that is given in Eq. 6.

$\mathrm{Nu}=0.47 \operatorname{Re}^{0.58} \operatorname{Pr}^{0.50}$

The effect of cooling performance on Titanium alloy plates using multiple jets with various nozzles was carried out experimentally by (He and Wen, 2017), and found that cross flow effect of multiple jets decreased the cooling effect over the plates. The experimental investigation of natural convection heat transfer enhancement from an 3 x 3 square $(12.7 \mathrm{~mm} \times 12.7 \mathrm{~mm}$ ) IC chips was carried out by (Heindel et al., 1995), and found that, heat transfer was enhanced by 24 times in a vertical orientation and 15 times in horizontal orientations of heat sources, and the maximum heat flux for vertical orientation was found to be $23.6 \mathrm{~W} / \mathrm{cm}^{2}$ with a maximum temperature of $70^{\circ} \mathrm{C}$, and for horizontal orientation, it was $28.2 \mathrm{~W} / \mathrm{cm}^{2}$, having a maximum temperature of $65^{\circ} \mathrm{C}$.

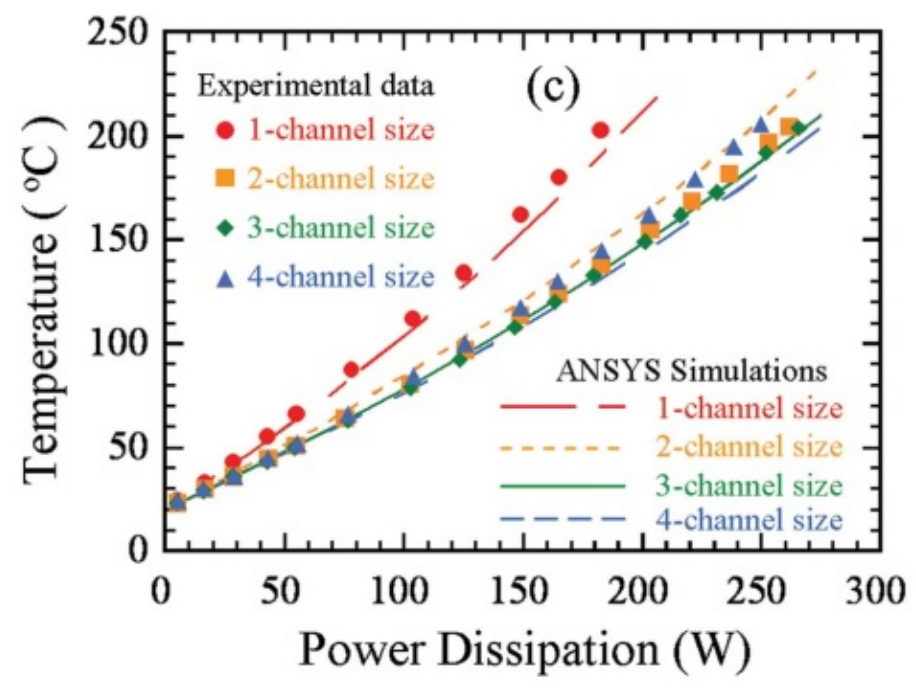

Fig. 4: Comparison between experimental and ANSYS data for the temperature of heat sources (Calame et al., 2009)

The experimental investigation was carried out by (Calame et al., 2009) for high heat flux removal from $\mathrm{BeO}$ ceramic and $\mathrm{GaN}$-on-SiC semiconductor dies using hierarchically branched microchannels. They found that $1.5 \mathrm{~kW} / \mathrm{cm}^{2}$ was removed from the $3.6 \mathrm{~mm} \times 4.7 \mathrm{~mm}$ resistive zone of the $\mathrm{BeO}$-based die at a surface temperature of $203^{\circ} \mathrm{C}$. The $\mathrm{BeO}$ based die can be used instead of high thermal conductivity GaN-on-SiC die with a $12.5 \mathrm{~mm} \times 5 \mathrm{~mm}$ resistive zone for a heat flux of $3.9 \mathrm{~kW} / \mathrm{cm}^{2}$. The comparison between experimental and ANSYS temperature data of different heat sources is shown in Fig. 4. The figure has shown a clear match between the experimental and numerical results. By increasing the power rating, the component temperature of chips has increased. Again, the chips in channel 1 have experienced higher temperature.

Experimental investigations were carried out by (Gersey and Muddawar, 1992) for different channel orientations to study the effect of critical heat flux (CHF) form nine in-line square microelectronic chips using FC-72. It was found that lowest CHF occurred when the bubbles stagnated on chip surface causing premature dry out, and highest $\mathrm{CHF}$ values were measured for up flow with the chips either upward or downward facing $\left(\theta=-45^{\circ}, 0^{\circ}, 45^{\circ}\right)$. The numerical and experimental investigation for cooling of electronic modulus for arrays of liquid jets was carried out by (Hosain et al., 2016). They found the impingement surface of rough concave dimples reduced the Nusselt number followed by an increase of $S / D_{j}$ ratio, for arrays of discrete heat sources. The experimental and numerical investigation has been carried by (Mcglen et al., 2004) to examine the jet impingement cooling combined with micro finned surfaces to enhance the thermal management of power electronic devices (resistors, diodes, logical gates etc.), and found that, at low power $(105 \mathrm{~W})$ the thermal resistance was reduced between $5-13 \%$ with micro 
fins. The experiments were also carried out to evaluate the reliability of micro fins. The experimental investigation was carried out by (Anderson and Muddawar, 1989) to study the effect of pool boiling on simulated square electronic chips using dielectric fluorocarbon (FC-72) in a vertically filled cavity. They have observed that the maximum heat flux is a function of surface geometry and orientation but independent of surface roughness.

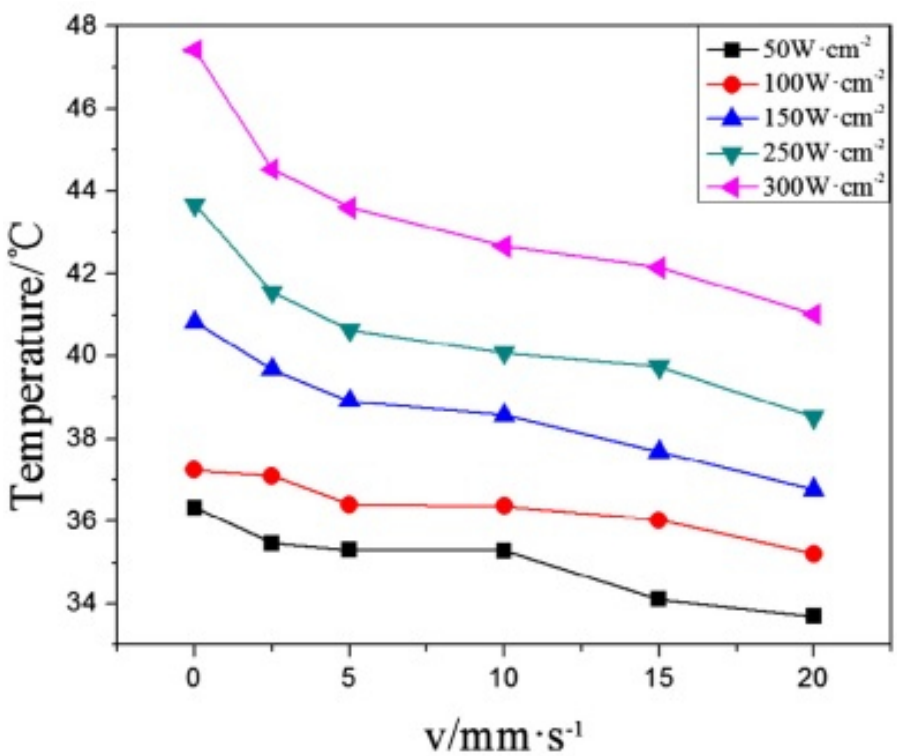

Fig. 5: Average Surface Temperature for different heat flux, $\mathrm{Re}=10120$ (Ai et al., 2017)

The experimental investigation of jet impingement using moving nozzles was studied by (Ai et al., 2017). They have also compared the heat transfer effect of fixed and moving nozzles. It was clear that moving nozzle performs better than a fixed nozzle for reducing the maximum temperature difference between the heating surface and the average liquid film thickness, which has resulted in better heat transfer rates and more uniform temperature, as shown in Fig. 5. The Fig. 5 has shown that the average substrate temperature and the Nusselt number has increased with increase in the nozzle velocity for different heat flux values. However, compared with a fixed nozzle, the effects of the moving nozzle are more significant at higher heat fluxes. The maximum average temperature difference was approximately $7^{\circ} \mathrm{C}$ and the Nusselt number has increased by $31 \%$ at the same heat flux.

\subsection{Numerical technique}

The numerical simulations (using Response Surface Approximation (RSA) and Multi-Objective Genetic Algorithms (MOGA)) for flow distribution were carried out by (Lam and Prakash, 2016), where they described heat transfer enhancement from chips. They found minimal entropy generation for jet impingement with $\mathrm{Al}_{2} \mathrm{O}_{3} /$ Water Nano-fluid. The numerical investigation to study the effect of geometrical parameters on the confined impinging jet heat transfer was studied by (Lou et al., 2005). They found that decrease of nozzle width and nozzle plate spacing resulted in an increase of heat transfer coefficient and ultimately Nusselt number. The numerical and experimental investigation of the effect of geometric and flow parameters on the Electronic cooling on square simulated electronic chips using free jets and sprays was made by (Estes and Mudawar, 1995), and suggested that the spray cooling is more effective for high heat flux removal from electronic components. They also found better single phase cooling performance and higher value of critical heat flux at the chip. The experimental and numerical investigation of natural convection heat transfer was carried out by (Gdhaidh, 2016) under liquid cooling medium using air and water. They carried out the simulations using ANSYS Icepack to study the heat transfer characteristics of unsteady and steady jets on high power electronics. (Leena et al., 2015) found that, heat transfer enhancement was due to construction and destruction of thermal and hydrodynamic boundary layer formation. They also proposed correlations for the Nusselt number in terms of Reynolds number for cooling of electronic chips. The numerical simulations with an axis-symmetric single and double jets using run out table cooling (ROT) technique (optimizes the use of water in the steel industry), and constant heat flux $\left(2.5 \mathrm{~W} / \mathrm{cm}^{2}\right)$, constant temperature boundary condition was carried out by (Hosain et al., 2016). The numerical investigation for cooling of four types of Nanoparticles $\mathrm{Al}_{2} \mathrm{O}_{3}, \mathrm{CuO}, \mathrm{ZnO}$, and $\mathrm{SiO}_{2}$ with water with different volume fractions of $1-5 \%$ was carried out by (Yarmand et al., 2014), and found that $\mathrm{SiO}_{2} /$ Water Nanofluid generate highest Nusselt number followed by $\mathrm{Al}_{2} \mathrm{O}_{3}, \mathrm{ZnO}, \mathrm{CuO}$ and pure water. $\mathrm{SiO}_{2}$ has lower heat transfer coefficient because of small thermal conductivity value among all the tested Nanofluids. The internal heat sink plays an important role in the heat removal from electronic components that lead to a temperature drop of $64.28^{\circ} \mathrm{C}$.

The temperature drop and amount of heat flux removal from electronic components along with type and size of components for a different type of analysis are given in Table 3. Many researchers have focused on experimental techniques by varying the channel orientation on which electronic components are mounted. The maximum heat flux removal rate obtained is of the order of $1-10000 \mathrm{~W} / \mathrm{cm}^{2}$, and the temperature drop is found to be $65-80^{\circ} \mathrm{C}$.

\section{CONCLUSION}

A detailed review was carried out for cooling of electronic components using liquid jet impingement. Most of the work was based on experimental and numerical analysis on single and arrays of square heat sources using water medium, under free and forced convection mode. A comparison study was also carried out using different working fluids for cooling of discrete heat sources. The broad summary of the review is given below.

(i) Electronic components under consideration: Microelectronic Chips, VLSI circuit chips, Integrated circuit (IC) chips, Resistors

(ii) Heat source size: Square

(iii) Heat source dimension: $10 \mathbf{m m}^{2}$ or $12.7 \mathbf{m m}^{2}$

(iv) Heat source type: Flush mounted or protruded

(v) Cooling fluid used: Water or Fluorocarbon liquid (FC72, FC-75, FC-77, FC-87, and R-113) or Dielectric Fluid (HFE-7200) or Nanofluids $\left(\mathrm{Al}_{2} \mathrm{O}_{3}, \mathrm{CuO}, \mathrm{TiO}_{2}\right.$ etc.)

(vi) Mode of heat transfer: Natural or Forced convection

(vii) Method of analysis: Numerical or Experimental

(viii) Reynolds Number: $\mathbf{8 0 0} \mathbf{- 3 0 0 0 0}$

(ix) The temperature drop from the component surface: $\mathbf{6 5}$ $85^{\circ} \mathrm{C}$

(x) Heat flux removal from the component surface: $150-600$ $\mathrm{W} / \mathbf{c m}^{2}$

\section{NOMENCLATURE}

$\mathrm{CP}_{\mathrm{P}} \quad$ specific heat of the liquid at constant pressure, $\mathrm{J} / \mathrm{kgK}$

D Duct Hydraulic diameter (4A/P)

Fo $\quad$ Fourier number, $\alpha \mathrm{t} / \mathrm{Hc}^{2}$

$\mathrm{H} \quad$ height of the channel, $\mathrm{m}$

$\mathrm{Hc} \quad$ height of the chip, $\mathrm{m}$

$\mathrm{H} / \mathrm{d} \quad$ Distance between the orifice plate and impingement surface (m)

h heat transfer coefficient, $W / \mathrm{m}^{2} \mathrm{~K}$ 
Table 3 Method of Analysis for Cooling of Electronic Modules using Liquid Jet impingement

\begin{tabular}{|c|c|c|c|c|}
\hline $\begin{array}{l}\text { Sl. } \\
\text { no. }\end{array}$ & Author(s) & $\begin{array}{l}\text { Method of } \\
\text { analysis }\end{array}$ & $\begin{array}{l}\text { Temperature drop / } \\
\text { Heat flux removal }\end{array}$ & Electronic Component (Size) \\
\hline 1 & Overholt, 2005 & Experimental & $300-1000 \mathrm{~W} / \mathrm{cm}^{2}$ & $\begin{array}{l}\text { Electronic components } \\
(1 \mathrm{~cm} \times 1 \mathrm{~cm})\end{array}$ \\
\hline 2 & Karwa, 2012 & Experimental & $8.5 \mathrm{~W} / \mathrm{cm}^{2}$ & Steel industries \\
\hline 4 & $\begin{array}{l}\text { Besserman et al., } \\
1991\end{array}$ & Experimental & $248 \mathrm{~W} / \mathrm{cm}^{2}$ & $\begin{array}{l}\text { Electrical heater } \\
(1.27 \mathrm{~cm} \times 1.27 \mathrm{~cm})\end{array}$ \\
\hline 5 & $\begin{array}{l}\text { Wadsworth } \\
\text { and Mudawar, } 1990\end{array}$ & Experimental & $100 \mathrm{~W} / \mathrm{cm}^{2}$ & $\begin{array}{l}\text { Square chips } \\
(1.27 \mathrm{~cm} \times 1.27 \mathrm{~cm})\end{array}$ \\
\hline 6 & Baker, 1972 & $\begin{array}{l}\text { Experimental } \\
\text { and Analytical }\end{array}$ & $500-10000 \mathrm{~W} / \mathrm{m}^{2}$ & $\begin{array}{l}\text { Small microelectronic chips, } \\
(2 \mathrm{~cm} \times 2 \mathrm{~cm}) \text { and Resistors }\end{array}$ \\
\hline 7 & Vanam et al., 2005 & Experimental & $140 \mathrm{~W} / \mathrm{cm}^{2}$ & $\begin{array}{l}\text { IGBT flip chips } \\
(1.5 \mathrm{~cm} \times 1.5 \mathrm{~cm})\end{array}$ \\
\hline 8 & Colgan et al., 2007 & Experimental & $63^{\circ} \mathrm{C}, 300-400 \mathrm{~W} / \mathrm{cm}^{2}$ & $\begin{array}{l}\text { High power Square IC chips } \\
(2 \mathrm{~cm} \times 2 \mathrm{~cm})\end{array}$ \\
\hline 9 & Leena et al., 2015 & $\begin{array}{l}\text { Experimental } \\
\text { and Numerical }\end{array}$ & $12000 \mathrm{~W} / \mathrm{m}^{2}$ & $\begin{array}{l}\text { Target surface } \\
(12 \mathrm{~cm} \times 12 \mathrm{~cm} \times 1 \mathrm{~cm})\end{array}$ \\
\hline 10 & $\begin{array}{l}\text { Maddox and } \\
\text { BarCohen, } 1994\end{array}$ & Experimental & $80{ }^{\circ} \mathrm{C}, 100 \mathrm{~W} / \mathrm{cm}^{2}$ & $\begin{array}{l}\text { Electronic chip } \\
(1 \mathrm{~cm} \times 1 \mathrm{~cm})\end{array}$ \\
\hline 11 & $\begin{array}{l}\text { Willingham } \\
\text { and Mudawar, } 1992\end{array}$ & Experimental & $40-50 \mathrm{~W} / \mathrm{cm}^{2}$ & $\begin{array}{l}\text { Square IC chips } \\
(1 \mathrm{~cm} \times 1 \mathrm{~cm})\end{array}$ \\
\hline 12 & Heindel et al., 1995 & Experimental & $65-80^{\circ} \mathrm{C}, 0.35-28.2 \mathrm{~W} / \mathrm{cm}^{2}$ & $\begin{array}{l}\text { Square IC chips } \\
(1.27 \mathrm{~cm} \times 1.27 \mathrm{~cm})\end{array}$ \\
\hline 13 & Calme et al., 2009 & Experimental & $1.5-3.9 \mathrm{~kW} / \mathrm{m}^{2}$ & Chips \\
\hline 14 & $\begin{array}{l}\text { Gersey and } \\
\text { Mudawar, } 1992\end{array}$ & Experimental & $0.13-120 \mathrm{~W} / \mathrm{cm}^{2}$ & $\begin{array}{l}\text { Square IC chips } \\
(1 \mathrm{~cm} \times 1 \mathrm{~cm})\end{array}$ \\
\hline 15 & Mcglen et al., 2004 & $\begin{array}{l}\text { Experimental } \\
\text { and Numerical }\end{array}$ & $17-20 \mathrm{MW} / \mathrm{m}^{2}$ & $\begin{array}{l}\text { Square IC chips } \\
(1 \mathrm{~cm} \times 1 \mathrm{~cm})\end{array}$ \\
\hline
\end{tabular}

$\mathrm{k}$ thermal conductivity of liquid, $\mathrm{W} / \mathrm{mK}$

1 length of heat source, $m$

$\mathrm{Nu}_{1} \quad$ Nusselt number based on heat source length, hl/k

$\mathrm{Nu}_{\mathrm{d}} \quad$ Average Nusselt number $\left(\mathrm{hD} / \mathrm{K}_{\mathrm{f}}\right)$

$\mathrm{Pe} \quad \quad$ Peclet number based on heat source length, $\mathrm{Re} / \mathrm{Pr}$

Pr Prandtl number of liquid

Q Volumetric flow rate, $\mathrm{m}^{3} / \mathrm{s}$

Rel Reynolds number based on heat source length, Ul/v

Red Reynolds number of the duct (WD $/ v)$

$t \quad$ time elapsed after the power $\mathrm{ON}, \mathrm{s}$

$\mathrm{U}$ flow velocity, Q/WH m/s

$\mathrm{W} \quad$ width of the channel, $\mathrm{m}$

Greek Symbols

$\alpha \quad$ thermal diffusivity of liquid, $\mathrm{k} / \rho \mathrm{C}_{\mathrm{p}}$

$\mu \quad$ dynamic viscosity of the liquid, $\mathrm{Ns} / \mathrm{m}^{2}$

$v \quad$ kinematic viscosity of the liquid, $\mu / \rho, \mathrm{m}^{2} / \mathrm{s}$

$\rho \quad$ density of liquid, $\mathrm{kg} / \mathrm{m}^{3}$

\section{ABBREVIATIONS}

CHF Critical Heat flux

IC Integrated chips

MCJA Microjet cooling arrays

MCHS Microchannel heat sink

MOGA Multi-objective genetic algorithm

ROT Run out Table Cooling

RSA Response surface method

\section{REFERENCES}

Agbim, K.A., 2017, "Single phase liquid cooling for Thermal Management of Power Electronic Devices," Ph.D. Thesis at Georgia Institute of Technology.

Agrawala, M.K., Modak, M., Gupta, P., Chandra, S., Sahu, S.K., 2014, "Experimental investigation to analyze the heat transfer characteristics of the hot surface by obliquely impinging liquid jet," Proceedings of the $5^{\text {th }}$ International and $41^{\text {st }}$ National Conference on Fluid Mechanics and Fluid Power, IIT Kanpur, UP, India.

Ai, X., Xu, Z. G., and Zhao, C.Y., 2017, "Experimental Study on Heat Transfer of Jet Impingement with a Moving Nozzle," Applied Thermal Engineering, 115, 682-691.

https://doi.org/10.1016/j.applthermaleng.2017.01.004

Ali, M. M., and Ramadhyani, S., 1992, "Experiments on convective Heat transfer in corrugated Channel," Experimental Heat transfer, 5, 175-193.

http://dx.doi.org/10.1080/08916159208946440

Amon, C. H., Yao, S. C., Wu, C. F., and Hsieh, C. C., 2005, "Microelectromechanical System-Based Evaporative Thermal Management of High Heat Flux Electronics," ASME Journal of Heat Transfer, 127, 66-75.

http://dx.doi.org/ 10.1115/1.1839586

Anderson, T. M., and Mudawar, I., 1989, "Microelectronic cooling by enhanced pool boiling of a Dielectric Fluorocarbon Liquid," ASME Journal of Heat Transfer, 111, 752-759. http://doi:10.1115/1.3250747

Anwarulla, M., 2011, "Experimental and theoretical investigation on the effect of geometric parameters in electronic components cooling using jet impingement," Ph.D. Thesis Submitted to JNTU Hyderabad.

Baker, E., 1972, "Liquid cooling of microelectronic devices by free and forced convection," Journal of microelectronic and reliability, 11(2), 213- 222.

https://doi.org/10.1016/0026-2714(72)90704-4

Besserman, D. L., Incropera, F. P., and Ramadhyani, S., 1991, "Experimental study of heat transfer from a discrete source to a circular 
liquid jet with an annular collection of the spent fluid," Experimental Heat Transfer, 4(1), 41-57.

http://dx.doi.org/10.1080/08916159108946404

Bhowmik, H., Tou, K. W, and Tso, C. P., 2004, "Water cooling study of natural convection heat transfer from simulated electronic chips during the power-on transient period," 20 ${ }^{\text {th }}$ IEEE Semi-Therm Symposium.

Bhowmik, H., Tou, K. W., 2005, "Study of transient forced convection heat transfer from discrete heat sources in an FC-72 cooled vertical channel," International Journal of Thermal Science, 44(5), 499-505. http://dx.doi.org/ 10.1016/i.ijthermalsci.2004.09.002

Bhowmik, H., and Tou, K. W., 2005, "Effect of the protrusion on the thermal transient behavior of chips in a liquid channel during the loss of pumping power," International Communication in Heat Mass Transfer, 32(1), 166 - 174.

http://dx.doi.org/10.1016/j.icheatmasstransfer.2004.05.017

Bhowmik, H., Tso, C. P., and Tow, K. W., 2003, "Thermal behavior of simulated chips during power off transient period," Electronics Packaging Technology Conference, 497 - 500.

Bhowmik, H., Tso, C. P., and Tou, K. W., 2005, "Analyses of convection heat transfer from discrete heat sources in the vertical rectangular channel," ASME Journal of Electronic Packaging, 127(3), 215-222.

http://dx.doi.org/ 10.1115/1.1938207

Calame, J. P., Park, D., Bass, R., Myers, R. E., Safier, P. N., 2009, "Investigation of hierarchically branched-micro channel coolers fabricated by deep reactive ion etching for electronics cooling applications," ASME Journal of Heat Transfer, 131(5) 1-9.

http://dx.doi.org/ 10.1115/1.3001017

Caromona, R., and Keyhani, M., 1989, "The Cavity Width Effect on Immersion Cooling Of Discrete Flush-Heater on One Vertical Wall of an Enclosure Cooled From the Top," ASME Journal of Electronic cooling packaging, 111(4), 268-276.

http://dx.doi.org/10.1115/1.3226546

Chang, H. Oh., Lienhard, V. H. John, H., Younis, H. F., Dahbura, R. S and Michels, D 1998 "Liquid jet array cooling modulus for high heat flux," AIChE J. 44(4), 769-779.

Chang, S.W., Chiou, S. F., and Chang, S. F., 2007, "Heat transfer of impinging jet array over concave dimple surface with application to cooling of electronic chipsets," Experimental Thermal Fluid Science, 31(7), $625-640$.

http://dx.doi.org/10.1016/j.expthermflusci.2006.06.008

Chein, R, and Chuang, J 2007 "Experimental microchannel heat sink performance studies using nano-fluids" International journal of thermal sciences, 46, 57-66.

https://doi.org/10.1016/i.ijthermalsci.2006.03.009
Chen, C. H., and Ding, C Y. 2011, "Study on the thermal behavior and cooling performance of a nanofluid-cooled microchannel heat sink," International Journal of thermal science, 50, 378-384. https://doi.org/10.1016/j.ijthermalsci.2010.04.020

Cheng, Y., Andrew A. O., Tay, X., and Hong, 2001, “An experimental study of liquid jet impingement cooling of electronic components with and without boiling," IEEE International Symposium on Electronic Materials and Packaging, 369-375

Cho, H.H., Kim, K.M., and Song, J., 2011, "Applications of impingement jet cooling systems," Cooling Systems Energy Engineering, and Applications first edition Nova Science Publishers, New York. 37-67

Colgan, E.G., Furman, B., Gaynes, M., Graham, W., LaBianca, N., Magerlein, J., Polastre, R.J., Rothwell, M, B., IBM Waston T.J. Research Center,1101 Kichawan Road, Yorktown Heights, NY 1059 Bezama, R. J., Choudhary, R. Marston, H. Toy, J. Wakil, J. Zitz. Colgan, 2007, Practical implementation of Si Microchannel Coolers $21^{\text {st }}$ IEEE SEMI-THERM symposium.

Estes Kurt, A., and Mudawar, I., 1995, "Comparison of two-phase electronic cooling using free jets and sprays." ASME Journal of Electronic Packaging, 117(4), 323-332.

https://doi:10.1115/1.2792112

Fabbri, M., and Dhir, V.K., 2005, "Optimized heat transfer for high power electronic cooling using arrays of the microjet," ASME Journal of Heat Transfer, 127(7), 760 - 769. http://dx.doi.org/10.1115/1.1924624

Flores, F. P., Trevino, C., and Suastegui, L. M., 2016, "Transient mixed convection heat transfer for opposing flow from discrete flushmounted heaters in a rectangular channel of finite length: Effect of buoyancy and inclination angle," International Journal of Thermal Sciences, 104, 357-372.

http://dx.doi.org/10.1016/j.ijthermalsci.2015.12.021

Gdhaidh, Farouq Ali. S., 2015, "Heat transfer Characteristics of Natural convection within an Enclosure Using the liquid cooling system," Ph.D. Thesis at School of Engineering and Informatics.

Gersey, C. O., and Muddawar, I., 1992, "Effects of orientation on critical heat flux from chip arrays during flow boiling," ASME Journal of Electronic Packaging 114(3), 290- 299. http://doi:10.1115/1.2905453

Gupta, A., and Jaluria, Y., 1998, "Forced convection liquid cooling of arrays of protruding heated elements mounted in a rectangular duct," ASME Journal of Electronic Packaging, 120(3) 243-252. http://doi:10.1115/1.2792629

Heindel, T. J., Incopera, F. P., and Ramadhyani, S., 1995, "Conjugate natural convection from an array of discrete heat sources: part-II - a numerical parametric study," International Journal of Heat and Fluid Flow, 16(6), 511-518. https://doi.org/10.1016/0142-727X(95)00057-W 
Heindel, T. J.., Ramadhyani, S., Incropera, F. R., 1995, "Conjugate natural convection from an array of discrete heat sources part-I-two and three-dimensional model validations," International Journal of Heat and Mass Transfer, 16(6), 501-510.

https://doi.org/10.1016/0142-727X(95)00058-X

Heindel, T. J., Ramadhyani, S., and Incopera, F. P., 1992, "Liquid immersion cooling of a longitudinal array of discrete heat sources in protruding substrates: I - Single phase convection," ASME Journal of Electronic Packaging, 114, 55-62.

http://doi:10.1115/1.2905442

Honnor, F., and Thomas, M. A., 1969, "Packaging and Cooling Problems Associated with Microelectronic Equipment," Pergamum Press, 8(4), 331-337.

https://doi.org/10.1016/0026-2714(69)90394-1

Hosain, M. L., Fdhila, R. B., and Daneryd, A., 2016, "Heat transfer by liquid jets impinging on a hot flat surface," Applied Thermal Engineering, 164, 934-943.

http://dx.doi.org/10.1016/j.apenergy.2015.08.038

Ijam, A and Saidur, R 2011 "Nanofluids as a coolant for electronic devices (cooling of electronic devices)" Applied thermal engineering, 32 76-82.

https://doi.org/10.1016/j.applthermaleng.2011.08.032

Incopera, F. P., 1988, "Convection heat transfer in electronic equipment cooling," ASME Journal of Heat Transfer, 1101097 1111.

http://doi:10.1115/1.3250613

Incropera, F. P., Kerby, J. S., Moffatt, D. F., and Ramadhyani, S., 1986 "Convective heat transfer from discrete heat sources in a rectangular channel", International Journal of Heat and Mass Transfer, 29(7), 1051-1058.

https://doi.org/10.1016/0017-9310(86)90204-8

Jaeger, R. C., Goodling, J. S., Baginsk, M. E., Charles, D., Williamson, E. V. M., and Obarr, R. M., 1989, "High heat flux cooling for Silicon hybrid multi-chip," IEEE Transactions on Components Hybrids and Manufacturing Technology, 12(4), 772 - 779.

http://doi: 10.1109/33.49046

Joshi, Y., and Paje, R. A., 1991 "Natural convection cooling of ceramic substrate mounted leadless chip carrier in dielectric liquids," International communications in heat and mass transfer, 18 (1), 3947.

https://doi.org/10.1016/0735-1933(91)90006-P

Joshi, Y., Wilson, T., and Hazard, S, J., 1989, "Experimental study of natural convection cooling of an array of heated protrusions in a vertical channel in water" ASME Journal of Electronic Packaging, 111, 33- 40 .

http://doi:10.1115/1.3226506

Kandilkar, S. G., and Bapat, A.V., 2007, "Evaluation of jet impingement, spray and microchannel chip cooling options for high heat flux removal," Heat Transfer Engineering, 28(11), 811-823. http://dx.doi.org/10.1080/01457630701421703
Karwa, N., 2012., "Experimental study of water jet impingement cooling of hot steel plates" Ph.D. Thesis Technical University Darmstadt.

Kiper, A. M., 1984, "Impinging water jet cooling of VLSI circuits," International Communications in Heat and Mass Transfer, 11(6), 517 - 524.

https://doi.org/10.1016/0735-1933(84)90003-4

Lam, P. A. K., and Prakash, K. A., 2016, "Thermodynamic investigation and multi-objective optimization for a jet impingement cooling system with $\mathrm{Al}_{2} \mathrm{O}_{3}$ /Water nanofluid," Energy Conversion and Management, 111, 38-56.

http://dx.doi.org/10.1016/i.enconman.2015.12.018

Lee, T. Y., Saylor, J., Simon, T., Tong, W., Wu, P. S., and Bar-Cohen, A., 1988, "Fluid Selection And Property Effect in Single and TwoPhase Immersion Cooling," IEEE Journal, 92-99

http://dx.doi.org/10.1109/ITHERM.1988.28685

Leena, R., Renjith, R. V., and Prakash, M. J., 2015 "Experimental and numerical investigations on steady and unsteady jet impingement cooling for high-power electronics," IEEE Transactions on Components Packaging and Manufacturing Technology, 5(5), 636640.

http://dx.doi.org/10.1109/TCPMT.2015.2420953

Leena, R., Syamkumar, G., and Prakash, M. J., 2018 Experimental and numerical analyses of multiple jet impingement cooling for high power electronics" IEEE Transactions on Components Packaging and Manufacturing Technology, 8(2) 210-215.

Lou, Z. Q., Mujumdar, A. S., and Yap, C., 2005, "Effects of geometric parameters on confined impinging jet heat transfer," Applied Thermal Engineering, 25(17), 2687-2697.

http://dx.doi.org/10.1016/j.applthermaleng.2004.10.014

Maddox, D. E., and Bar-Cohen, A., 1994, "Thermo-fluid Design of single phase submerged jet impingement cooling for electronic components," ASME Journal of Electronic Packaging, 116(3), $237-$ 240.

http://doi:10.1115/1.2905692

Maddox, J. F., Roy, W. K., Bhavamani, S. H., and James, P., 2016, "Correlation for Single Phase Liquid Jet Impingement with an Angled Confining Wall for Power Electronics Cooling," 15th IEEE ITHERM Conference, 978(1) 46-73.

Mahaney, H. V., Incropera, F. P., and Ramdhyani, S., 1990, "Measurement of mixed convection heat transfer from an array of discrete sources in a horizontal rectangular channel with and without surface augmentation," Experimental Heat Transfer, 3(3), 215 - 237. http://dx.doi.org/10.1080/08916159008946387.

Mcglen, R. J., Jachuck, R., and Lin, S., 2004, "Integrated thermal management techniques for high power electronic devices," Applied Thermal Engineering, 24(8), 1143-1156.

http://dx.doi.org/10.1016/j.applthermaleng.2003.12.029 
Mudawar, I, and Maddox, D. E., 1989, "Critical heat flux in subcooled flow boiling of fluorocarbon liquid on a simulated electronic chip a vertical rectangular channel", International Journal of Heat and Mass Transfer, 32(2), 379-394.

https://doi.org/10.1016/0017-9310(89)90184-1

Mudawar, I., and Maddox, D. E., 1990, "Enhancement of critical heat flux from high-power microelectronic heat sources in a flow channel," ASME Journal of Electronic Packaging, 112 (3), 241-248 http:// dx.doi:10.1115/1.2904373

Naphon, P., and Wongwises, S., 2011, "Experimental study of jet Nano-fluids impingement system for cooling computer processing unit," Journal of Electronic Cooling and Thermal Control, 1, 38-44. http://dx.doi.org/ 10.4236/jectc.2011.13005

Overholt, M. R., McCandless, A., Kelly, K. W., Becnel, S. and Motakef., C. J., 2005, "Microjet arrays for cooling of electronic equipment," Proceedings of ASME $3^{\text {rd }}$ International Conference of Microchannels and Mini channels Toronto, Ortanto, Canada. 1-4

Reynell, M., 1990 "Major causes for failure of electronic components," U.S.Air Force Avionics Integrity Program.

Roberts, N. A and Walker, D. G 2010 "Convective performance of nanofluids in commercial electronics cooling systems," Applied thermal engineering, 30, 2499-2504.

https://doi.org/10.1016/j.applthermaleng.2010.06.023

Robinson, A. J., and Schnizler, E., 2007, "Experimental investigation of free and submerged miniature liquid jet array impingement heat transfer," Experimental Thermal and Fluid Science, 32(1), 1-13. http://dx.doi.org/10.1016/i.expthermflusci.2006.12.006

Samant, K. R., and Simon, T. W., 1989, "Heat Transfer From a small Heated Region to R-113 and F-72," ASME Journal of Heat Transfer, 111(4), 1053-1059.

http://dx.doi:10.1115/1.3250767

Schafer, D., Incropera, F. P., and Ramadhyani, S., 1991, "Planar liquid jet impingement cooling of multiple discrete heat sources", ASME Journal of Electron Packaging, 113(4), 359 - 367. http://dx.doi:10.1115/1.2905421

Senthil Nayaki, V. P. M., Saravanan, S., Niu, X. D., Kandaswamy, P., 2017, "Natural convection cooling of Arrays of flush mounted discrete heaters inside a 3D cavity," Advances in Applied Mathematics and Mechanics, 9 (3), 698-721.

Sharma, C. S., Zimmermann, S., Tiwari, K. M., Michel, B., and Poulikakos, D., 2012, "Optimal thermal the operation of liquid-cooled electronic chips," International journal of heat and mass transfer, 55(7), 1957-1969.

http://dx.doi.org/10.1016/j.ijheatmasstransfer.2011.11.052

Singh, S., Singh, R., and Thakur, H., 2016, "Enhancement of Cooling in Central Processing CPU by Using Jet Impingement With And Without Nano Fluid," International Journal for Innovative Research in Science \& Technology, 2 (10), 9-16.
Sohel, M. R, Khaleduzzaman, S. S., Saidur, R., Hepbasli, A., Sabri, M. F. M. and Mahbubul, I. M., 2014 " Experimental investigation of heat transfer enhancement of a minichannel heat sink using $\mathrm{Al}_{2} \mathrm{O}_{3}-\mathrm{H}_{2} \mathrm{O}$ nanofluids" International journal of heat and mass transfer, 74, 164172.

https://doi.org/10.1016/i.ijheatmasstransfer.2014.03.010

Sung, M. K., and Muddwar, I., 2006, "Correlation of critical heat flux in hybrid jet impingement/micro-channel cooling scheme," International Journal of Heat and Mass Transfer, 49(15), 2663-2672. https://doi.org/10.1016/j.ijheatmasstransfer.2006.01.008

Teamah, M. A., and Khairat, M. M., 2015, "Heat transfer due to impinging double free circular jets," Alexandria Engineering Journal, 54, 281-293.

http://dx.doi.org/10.1016/j.aej.2015.05.010

Tou, K. W., Xu, G. P., and Tso, C. P., 1998, "Direct liquid cooling of electronic chips by single-phase forced convection of FC-72," Experimental Heat Transfer, 11 121-134. http://dx.doi.org/10.1016/j.icheatmasstransfer.2004.05.017

Tso, C. P., Xu, G. P., and Tou, K.W., 1999, "Experimental study on forced convection heat transfer from flush-mounted discrete heat sources," ASME Journal of Heat Transfer, 121(2) 326 - 333. http://dx.doi:10.1115/1.2825984

Tuckerman, B. D., 1984, "Heat Transfer Microstructures for Integrated circuits," Ph.D. Thesis at School of Mechanical Engineering at Stanford University.

Vanam, K., Junghans, J., Barlow, F., Selvam, R. P., Balda J.C., and Elshabini A., 2005, "Novel packaging methodology for spray cooling of power semiconductor devices using Dielectric liquids," Applied Power Electronics Conference and Exposition, 2014 - 2018. ieeexplore.ieee.org/ie15/9847/31031/01453335.pdf

Wadsworth, D. C., and Mudawar, I., 1990, "Cooling of a multiple chip electronic module by means of confined two-dimensional jets of dielectric liquid," ASME Journal of Heat and Mass Transfer, 112, 891898.

http://doi:10.1115/1.2910496

Wang, D., Yu, E., and Pezekwas, A., 1999, "Computational study of two-phase jet impingement cooling of an electronic chip," $15^{\text {th }}$ IEEE Semi-Thermo Symposium, 10 - 15.

Wang, E. N., Zhang, L., Jiang, L., Koo, J. M., Maveety, J. G., Sanchez, E. A., Goodson, K. E., 2004 "Micromachined Jets for Liquid Impingement Cooling of VLSI Chip," Journal of micromechanical systems, 13(5), 833-842.

http://.dx.doi: 10.1109/JMEMS.2004.835768

Whelan, B. P., Kempers, K., Robinson, A. J., 2012, "Liquid-Based system for CPU cooling implementing a jet array impingement water block and a tube array remote heat exchanger," Applied Science engineering Journal 39, 86-94. http://dx.doi.org/10.1016/i.applthermaleng.2012.01.013 
Willingham, T. C., and Muddwar, I., 1991, "Forced convection boiling and critical heat flux from a linear array of discrete heat sources," International Journal of Heat and Mass Transfer, 35(11), 2879-2890. https://doi.org/10.1016/0017-9310(92)90308-F

Womac, D. J., Ramadhyani, S., and Incropera, F. P., 1993 “Correlating equations for impingement cooling of small heat sources with single circular liquid jets," ASME Journal of Heat Transfer, 115(1), 106-115. http://doi:10.1115/1.2910635

Yarmand, H., Gharehkhani, S., Kazi, S. N., Sadeghinezab, E., and Safael, M. R., 2014, "Numerical investigation of heat transfer enhancement in the rectangular heated pipe for turbulent nanofluid," The Scientific World Journal, 1-9.

http://dx.doi.org/10.1155/2014/369593 